\title{
Subsidizing artemisinin-based combination therapies: a preliminary investigation of the Affordable Medicines Facility - malaria
}

This article was published in the following Dove Press journal:

Research and Reports in Tropical Medicine

17 July 2012

Number of times this article has been viewed

\author{
Roger Bate ${ }^{1,2}$ \\ Kimberly Hess ${ }^{2}$ \\ Richard Tren ${ }^{2}$ \\ Lorraine Mooney ${ }^{3}$ \\ Franklin Cudjoe 4 \\ Thompson Ayodele ${ }^{5}$ \\ Amir Attaran ${ }^{6}$ \\ 'American Enterprise Institute, \\ Washington, DC, USA; ${ }^{2}$ Africa Fighting \\ Malaria, Washington, DC, USA; \\ ${ }^{3}$ Africa Fighting Malaria, Cambridge, \\ United Kingdom; ${ }^{4}$ IMANI Center for \\ Policy and Education, Accra, Ghana; \\ ${ }^{5}$ Initiative for Public Policy Analysis, \\ Lagos, Nigeria; 'University of Ottawa, \\ Ottawa, ON, Canada
}

Background: The Affordable Medicines Facility - malaria (AMFm) is a subsidy mechanism to lower the price of, and hence increase access to, the best antimalarial medicines, artemisininbased combination therapies (ACTs). While the AMFm stipulates that only quality-approved products are eligible for subsidy, it is not known whether those products, when actually supplied, are of good quality and comport with established pharmacopeial guidance on formulation and content of active ingredients. This study aimed to assess price and quality of AMFm ACTs, to compare AMFm ACTs with non-AMFm ACTs and artemisinin monotherapies, and to assess whether AMFm ACTs have been pilfered and diverted to a nearby country.

Methods: In all, 140 artemisinin-based antimalarial drugs were acquired from 37 pharmacies in Lagos, Nigeria, and Accra, Ghana. An additional ten samples of AMFm ACTs were collected from Lomé, Togo (not participating in the AMFm). Samples were analyzed using high-performance liquid chromatography.

Results: The AMFm ACTs were lower in price than many of the other drugs collected, but by less than anticipated or stipulated by the participating governments of Nigeria and Ghana. The quality of the AMFm ACTs was not universally good: overall, 7.7\% had too little active pharmaceutical ingredient (API) and none had too much - these results are not likely to be as a result of random chance. AMFm ACTs were also found to have been diverted, both to pharmacies in Lagos not participating in the AMFm and to a foreign city (Lomé) where the AMFm is not operational.

Conclusion: The AMFm is at best imperfectly displacing undesirable monotherapies, some portion of which are replaced by ACTs lacking sufficient API, which are often sold at prices exceeding government authorization. ACTs sold at a lower price with low-dose API, potentially extrapolated to approximately 100 million treatments ordered under the AMFm for Nigeria and Ghana, represent a possible concern to public health and the promotion of drug resistance.

Keywords: high-performance liquid chromatography, antimalarial drugs, active pharmaceutical ingredient, Ghana, Nigeria

\section{Introduction}

The Affordable Medicines Facility - malaria (AMFm) is a financing mechanism hosted by The Global Fund to Fight AIDS, Tuberculosis and Malaria (GF) and designed to expand access to the best malaria treatments, which at present are artemisinin-based combination therapies (ACTs). The GF first negotiates a reduced price for ACTs with manufacturers. When an order occurs for an ACT, the GF pays most of this reduced price (termed a "buyer co-payment") directly to the manufacturer, with the balance paid by eligible wholesalers (termed "first-line buyers") in participating countries. In practice, first-line buyers pay under $10 \%$, or as little as $3 \%$, of the true sale price. ${ }^{1}$ They in turn are expected to pass on this price reduction, so that ACTs in the public,
Correspondence: Roger Bate American Enterprise Institute, II 50 Seventeenth Street, NW, Washington, DC 20036, USA

Tel +l 2028286029

Fax +l 2028627177

Email rbate@aei.org 
private, or not-for-profit sectors are available to patients at prices cheaper than less effective competing treatments such as artemisinin monotherapies, chloroquine, sulfadoxinepyrimethamine, and poor-quality medicines of all kinds. ${ }^{1}$

The AMFm has several public health goals: (1) to compete aggressively on price against less desirable medicines and to drive these from the market; (2) to reduce recourse to counterfeit and substandard drugs; (3) to ensure that the ACTs on the market conform with minimum pharmacopeial quality standards; and (4) in the long term, to minimize the selective pressures promoting ACT resistance and treatment failure. It is clear that some progress has been made on the first two goals, but there has been little study of the third goal, upon which the attainment of the fourth goal depends.

This study was conducted in Accra, Ghana, and Lagos, Nigeria, as with previous studies. ${ }^{2}$ The authors set out to assess the price and quality of a sample of AMFm ACTs, and a secondary aim was to compare those AMFm ACTs with a smaller sample of non-AMFm ACTs and artemisinin monotherapies. Since it is known that theft and international diversion of subsidized public sector product is a problem, ${ }^{3}$ a tertiary aim was to sample a setting outside the AMFm scheme (Lomé, Togo) to assess whether AMFm ACTs have been pilfered and diverted to this nearby country. (ACTs displaying an AMFm logo on packaging are herein referred to as "AMFm ACTs"; antimalarial drugs not produced by AMFm-approved manufacturers and therefore lacking an AMFm logo are referred to as "non-AMFm drugs.")

\section{Methods}

In May 2011, samples of oral artesunate monotherapy, dihydroartemisinin monotherapy, artemether-lumefantrine fixed-dose combination, artesunate-amodiaquine fixeddose combination, artesunate-amodiaquine co-blister, and dihydroartemisinin-piperaquine co-blister were collected from 22 pharmacies in Lagos and 15 pharmacies in Accra. Four local nationals posing as casual customers (without a prescription or confirmed diagnosis) seeking malaria treatment obtained the drug samples. The "customers" bought from private pharmacies in five typical areas, neither exceptionally rich nor poor, of each city, proceeding on a random walk in each area until antimalarial drugs had been procured from at least three pharmacies self-identified as participating in the AMFm. Drugs were also procured from non-AMFmapproved pharmacies if they were selling AMFm ACTs. The "customers" were instructed to buy a selection of antimalarial

Table I Average drug cost (in US dollars) and markup by formulation and presence of the Affordable Medicines Facility - malaria (AMFm) logo

\begin{tabular}{|c|c|c|c|c|c|}
\hline \multirow[t]{2}{*}{ Formulation $^{a}$} & \multirow[t]{2}{*}{ Variable } & \multicolumn{2}{|c|}{ Non-AMFm drugs ${ }^{b}$} & \multicolumn{2}{|c|}{ AMFm ACTs ${ }^{c}$} \\
\hline & & Adult & Child & Adult & Child \\
\hline Artesunate-amodiaquine & Overall average cost & $\$ 4.28$ & $\$ 3.29$ & $\$ 2.48$ & $\$ 1.64$ \\
\hline fixed-dose combination & Overall average markup ${ }^{d}$ & $\mathrm{~N} / \mathrm{A}$ & $\mathrm{N} / \mathrm{A}$ & 2.99 & 6.67 \\
\hline \multirow[t]{4}{*}{ and co-blister } & Average cost in Lagos ${ }^{e}$ & N/A & N/A & $\$ 2.34$ & $\$ 1.60$ \\
\hline & Average markup in Lagos ${ }^{f}$ & $N / A$ & $\mathrm{~N} / \mathrm{A}$ & 3.06 & 8.33 \\
\hline & Average cost in Accra ${ }^{g}$ & $\$ 4.28$ & $\$ 3.29$ & $\$ 2.80$ & $\$ 1.64$ \\
\hline & Average markup in Accra ${ }^{h}$ & $N / A$ & $N / A$ & 2.83 & 6.25 \\
\hline Artemether-lumefantrine & Overall average cost & $\$ 4.40$ & $\mathrm{~N} / \mathrm{A}$ & $\$ 2.31$ & $\$ 2.01$ \\
\hline \multirow[t]{5}{*}{ fixed-dose combination } & Overall average markup & N/A & $\mathrm{N} / \mathrm{A}$ & 2.82 & 6.98 \\
\hline & Average cost in Lagos & $\mathrm{N} / \mathrm{A}$ & $\mathrm{N} / \mathrm{A}$ & $\$ 2.45$ & $\$ 2.24$ \\
\hline & Average markup in Lagos & $\mathrm{N} / \mathrm{A}$ & $\mathrm{N} / \mathrm{A}$ & 3.20 & 3.89 \\
\hline & Average cost in Accra & $\$ 4.40$ & $\mathrm{~N} / \mathrm{A}$ & $\$ 2.02$ & $\$ 1.97$ \\
\hline & Average markup in Accra & $\mathrm{N} / \mathrm{A}$ & $\mathrm{N} / \mathrm{A}$ & 2.05 & 7.50 \\
\hline Dihydroartemisinin-piperaquine & Overall average cost & $\$ 3.29$ & $\mathrm{~N} / \mathrm{A}$ & $N / A$ & N/A \\
\hline \multirow[t]{2}{*}{ co-blister } & Average cost in Lagos & $\mathrm{N} / \mathrm{A}$ & $\mathrm{N} / \mathrm{A}$ & $\mathrm{N} / \mathrm{A}$ & N/A \\
\hline & Average cost in Accra & $\$ 3.29$ & $\mathrm{~N} / \mathrm{A}$ & $\mathrm{N} / \mathrm{A}$ & N/A \\
\hline Dihydroartemisinin & Overall average cost & $\$ 2.50$ & $\mathrm{~N} / \mathrm{A}$ & $\mathrm{N} / \mathrm{A}$ & $\mathrm{N} / \mathrm{A}$ \\
\hline \multirow[t]{2}{*}{ monotherapy } & Average cost in Lagos & $N / A$ & $\mathrm{~N} / \mathrm{A}$ & $N / A$ & N/A \\
\hline & Average cost in Accra & $\$ 2.50$ & $\mathrm{~N} / \mathrm{A}$ & $N / A$ & $\mathrm{~N} / \mathrm{A}$ \\
\hline \multirow[t]{3}{*}{ Artesunate monotherapy } & Overall average cost & $\$ 2.03$ & $\mathrm{~N} / \mathrm{A}$ & $\mathrm{N} / \mathrm{A}$ & $\mathrm{N} / \mathrm{A}$ \\
\hline & Average cost in Lagos & $\$ 1.87$ & $\mathrm{~N} / \mathrm{A}$ & $\mathrm{N} / \mathrm{A}$ & $\mathrm{N} / \mathrm{A}$ \\
\hline & Average cost in Accra & $\$ 3.62$ & N/A & N/A & N/A \\
\hline
\end{tabular}

Notes: artesunate-amodiaquine fixed-dose combination and co-blister, artemether-lumefantrine fixed-dose combination, and dihydroartemisinin-piperaquine co-blister are ACTs; ${ }^{b}$ collected antimalarial drugs lacking an AMFm logo on packaging; 'collected antimalarial drugs displaying an AMFm logo on packaging; ${ }^{d}$ no markup data available for antimalarial drugs lacking an AMFm logo on packaging; ${ }^{\mathrm{c}}$ cost based on conversion rate of USD I = NGN I56.5; ' $m$ markup based on expected price of NGN I20 per adult course and NGN 30 per child course (NGN 90 was used for the one child course of 18 pills per pack); ${ }^{8}$ cost based on conversion rate of USD I = GHS I.52; ${ }^{\circ}$ markup based on expected price of GHS 1.5 per adult treatment and GHS 0.40 per child treatment.

Abbreviations: ACTs, artemisinin-based combination therapies; GHS, Ghanaian cedi; N/A, not applicable; NGN, Nigerian naira; USD, US dollars. 
drugs from each pharmacy and to buy AMFm ACTs where possible. Since the sampling method was constrained by these minimums the resulting sample is quasi-random, insofar as it includes at least $30 \mathrm{AMFm}$ participating pharmacies, which may be of higher quality than pharmacies not participating in the AMFm.

A variant of this method was used in Lomé: the "customer" visited both street markets and official pharmacies, buying AMFm ACTs. Since Togo is not a country in which the AMFm operates, all AMFm ACTs collected in this way are most likely to have been unlawfully diverted or stolen.

The drug samples were stored at ambient temperature, with low humidity and no sunlight, pending testing conducted at least 3 months before product expiry. Initial screening of the drug samples from Accra and Lagos was conducted following the Global Pharma Health Fund eV Minilab ${ }^{\circledR}$ protocol. ${ }^{4}$ One hundred and fifty artemisinin-based antimalarial drug samples were then analyzed using the "gold standard" laboratory technique of high-performance liquid chromatography (HPLC) for deviations from active pharmaceutical ingredient (API) standards in order to determine if a greater number of products appeared suspect than were found using thin-layer chromatography alone. ${ }^{5}$

Under the World Health Organization International Pharmacopoeia, generally the acceptable range for current artemisinin-based antimalarials and their companion drugs is to contain $90.0 \%$ to $110.0 \%$ of the active ingredient stated on the label, although allowances are made for losses in HPLC testing such that an average of $75 \%$ may be considered acceptable. ${ }^{6}$ We therefore adopt a wider tolerance band of $75 \%$ to $125 \%$ for the purposes of this study, which conservatively would tend to understate failures of drug quality.

\section{Results}

Of the 37 pharmacies sampled in Lagos and Accra, each sold AMFm and non-AMFm drugs, although only 30 of those pharmacies self-identified as participating in the AMFm. The seven nonparticipating pharmacies were all in Lagos. This demonstrates that within AMFm countries such as Nigeria, diversion of medicines outside authorized AMFm supply channels exists, although the pathways of diversion (eg, theft, loss) are unknown.

A total of 166 antimalarial drug samples were collected from Accra and Lagos: 75 from Lagos and 65 from Accra were artemisinin-based antimalarial drugs and were further

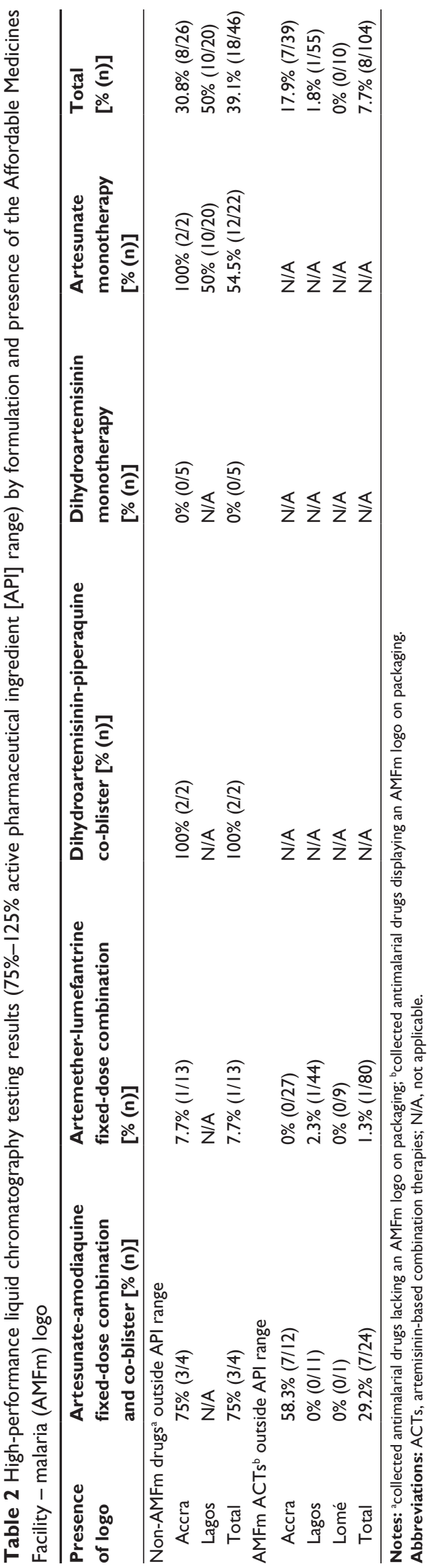


tested by HPLC; 26 were non-artemisinin drugs, were not in tablet form or had expired, and were not further tested by HPLC. From Lomé, ten ACT samples were collected, comprising seven batches of five separate formulations of ACTs. The total number of artemisinin-based products from all sites for analysis was 150 .

Among the 150 artemisinin-based medicines tested by HPLC, 46 were non-AMFm drugs and 104 were AMFm ACTs. Adult AMFm ACTs (average, US\$2.34; mode, US\$1.92; range, US\$0.99-US\$4.61) were cheaper overall than the adult non-AMFm ACTs (average, US\$4.26; mode, US\$4.61; range, US\$1.32-US\$9.87). AMFm ACTs, such as adult artesunate-amodiaquine fixed-dose combination and co-blister (average, US\$2.48; mode, US\$3.29 and US\$1.92; range, US\$1.28-US\$3.29) or adult artemether-lumefantrine (average, US\$2.31; mode, US\$1.92; range, US\$0.99US\$4.61), were about the same price as non-AMFm dihydroartemisinin monotherapy (average, US\$2.50; mode, US\$2.63; range, US\$1.97-US\$2.63); however, artesunate monotherapy was found to be cheaper than both (average, US\$2.03; mode, US\$1.92; range US\$1.60-US\$5.26). Thus AMFm ACTs were cheaper than some but not all alternatives in the market (see Table 1).

AMFm ACTs were found to be frequently sold above the anticipated price. According to documents from the GF board, adult treatments are expected to be sold at 120 Nigerian naira (NGN) and child treatments are expected to be sold at NGN 30 in Nigeria. ${ }^{7}$ Furthermore, adult Coartem ${ }^{\circledR}$ collected in Nigeria had packaging with the price NGN 120 printed on it. According to the Ghana Health Service and a Health Action International report, adult treatments are expected to be sold at 1.5 Ghanaian cedi (GHS) and child treatments at GHS 0.40 in Ghana. ${ }^{8,9}$ The average markup for the AMFm ACTs collected in Lagos and Accra was calculated based on these expected, though not mandated, prices. The average markup for adult artesunate-amodiaquine fixed-dose combination and co-blister was 2.99 times the expected price; the average markup for adult artemether-lumefantrine was 2.82 times the expected price (see Table 1). The average markup for child artesunate-amodiaquine fixed-dose combination and co-blister was 6.67 times the expected price; the average markup for child artemether-lumefantrine was 6.98 times the expected price. (Note: these figures possibly underestimate markups in Nigeria, according to a report published in June 2011 indicating a lower expected price of NGN 75 per adult treatment. ${ }^{9}$ )

Overall, following the Minilab protocol, two (1.4\%) of 140 antimalarial drug samples (excluding the ten samples from Lomé) contained no API and were probably falsified products. Both were samples of the artesunate monotherapy Artesunat ${ }^{\circledR}$, which has been identified in the literature as a product often falsified. ${ }^{10,11} \mathrm{~A}$ further nine products $(6.4 \%)$ were considered suspect (because of unusual packaging, degraded appearance, or containing barely enough API).

All 150 artemisinin-based products from Lagos, Accra, and Lomé were assessed using HPLC. This showed 39.1\% (18/46) of non-AMFm drugs and 7.7\% (8/104) of AMFm ACTs had too little API ( $<75 \%)$ (see Table 2$)$. The mean of the artemisinin API component is $86.5 \%$ (95\% confidence interval, 84.59383-88.47732; $t=-13.7523$ ) (see Table 3), and the data are normally distributed (Shapiro-Wilk $W$ test, 0.96415; Prob $>z, 0.00647$ ) (see Table 4), supporting the notion that the results are not likely to be one of random chance. Additionally, for the companion drug of the AMFm ACTs, either lumefantrine or amodiaquine, the mean API is $98.6 \%$ and none have below $75 \% \mathrm{API}$, which promotes the likelihood that underdosing of artemisinin API content is not random.

Among AMFm ACTs, artesunate-amodiaquine was more frequently substandard than artemether-lumefantrine $(29.2 \%$ and $1.3 \%$, respectively), indicating that the AMFm imprimatur does not assure a single standard of quality assurance, but instead depends on the specific ACT formulation.

\section{Discussion}

It is of great concern that almost $40 \%$ of the non-AMFm drugs sampled have incorrect amounts of API in them, and

Table 3 Student's $t$-test results by presence of the Affordable Medicines Facility - malaria (AMFm) logo

\begin{tabular}{|c|c|c|c|c|c|}
\hline Presence of logo & Observed artemisinin mean (\%) & SE & $95 \% \mathrm{Cl}$ & $t$-value & DF \\
\hline AMFm ACTs $s^{a}$ & 86.53558 & 0.9790648 & $84.59383-88.47732$ & -13.7523 & 103 \\
\hline Non-AMFm drugs ${ }^{b}$ & 75.29783 & 2.992279 & $69.270 I-81.32459$ & -8.2553 & 45 \\
\hline $\begin{array}{l}\text { Both AMFm and non-AMFm } \\
\text { drugs combined }\end{array}$ & 83.089 & 1.211986 & $80.69443-85.48423$ & -13.9529 & 149 \\
\hline
\end{tabular}

Notes: accollected antimalarial drugs displaying an AMFm logo on packaging; bollected antimalarial drugs lacking an AMFm logo on packaging.

Abbreviations: $\mathrm{ACT}$, artemisinin-based combination therapies; $\mathrm{Cl}$, confidence interval; DF, degrees of freedom; $\mathrm{SE}$, standard error. 
Table 4 Shapiro-Wilk $W$ test results by presence of the Affordable Medicines Facility - malaria (AMFm) logo

\begin{tabular}{llll}
\hline Presence of logo & W statistic & z statistic & Prob $>$ z \\
\hline AMFm ACTs $^{\mathrm{a}}$ & 0.96415 & 2.485 & 0.00647 \\
Non-AMFm drugs $^{\mathrm{b}}$ & 0.74380 & 5.413 & 0.00000 \\
Both AMFm and non-AMFm & 0.80925 & 7.028 & 0.00000 \\
drugs combined & & & \\
\hline
\end{tabular}

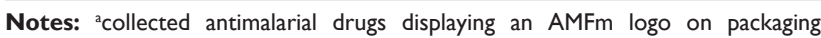
bcollected antimalarial drugs lacking an AMFm logo on packaging.

Abbreviation: ACTs, artemisinin-based combination therapies.

it is of equal concern that $7.7 \%$ of the AMFm ACTs also fall into this category. Fortunately, no AMFm ACTs were found to have been obviously falsified.

Concerns regarding the quality of AMFm ACTs, while not being as bad as for non-AMFm drugs, nonetheless exist. While the AMFm stipulates that only quality-approved products are eligible for subsidy, it is not known whether those products, when actually supplied, are of good quality. A recent study suggests that there may be some weakness in postmarketing surveillance of products approved by the World Health Organization. ${ }^{12}$ Over 100 million treatments of AMFm ACTs have been ordered for Ghana and Nigeria alone. ${ }^{13}$ Hypothetically, if the results of this relatively small study were simply extrapolated across this supply, it could mean over 7 million treatments of ACTs could be underdosed.

In order to state conclusively why the few AMFm ACTs collected and analyzed for this study were substandard, laboratory analysis would need to be conducted on a much larger number of samples outside Accra and Lagos. However, the substandard medicines identified in this study always contained too little API $(<75 \%)$ and never contained too much $(>125 \%)$, and these results are not likely to be of random chance. Such results are of serious concern when too little API will promote drug resistance and endanger public health. Products may have degraded, but most of the AMFm ACTs tested were within 1 year of their date of manufacture.

The AMFm aims to reduce the price of ACTs so as to compete with monotherapies and thereby drive monotherapies out of the market. However, this cannot be accomplished as long as the price of ACTs remains higher than monotherapies, as was found in pharmacies in both cities assessed in this study. The results suggest that the objective of driving out monotherapies and older therapies from the market may be more difficult than anticipated, since 73\% (27/37) of the pharmacies (including those participating in the AMFm) visited in Accra and Lagos were still selling monotherapies.
The AMFm aims to increase use of ACTs,${ }^{14}$ which is a desirable objective provided effective price and distribution controls are in place. Medicines intended for AMFm countries were found diverted to Togo, where their sale is not authorized. AMFm ACTs were found being sold at higher prices in Lagos and Accra than the prices stipulated by the participating governments - for child treatments, sometimes as much as ten times the expected price (eg, two samples of child artemether-lumefantrine found in an Accra pharmacy were selling for GHS 4, not GHS 0.40). Even though the AMFm is managing to decrease the price of ACTs, it remains far from achieving the price reductions that are claimed.

\section{Conclusion}

The GF and AMFm funders are to be commended for exploring innovative solutions to increase access to safe and effective malaria medicines. However, the quality of AMFm ACTs as shown in this rather small sampling is not universally good, even when measured at the most generous limits of acceptable drug quality ( $75 \%-125 \%$ API range). Of special concern is the likelihood, shown to a statistically significant level, that substandard medicines are not occurring randomly but, rather, are probably occurring through undetected manufacturing practices that cause, in this study, all substandard AMFm ACTs to have too little API and none to have too much. Furthermore, these substandard medicines are generally for sale above the governmentstipulated price and are not sold at a price low enough to have displaced artemisinin monotherapies, which remain on the market. Taken together, these results warn that the AMFm program may not be operating in such a way as to remove the threat of artemisinin resistance, which was the principal reason that the program was created. With a total budget of US\$225 million for Phase 1, the AMFm carries significant opportunity costs and it is a concern that these early results, though based on a small sample size, are not more encouraging.

\section{Acknowledgments}

The authors would like to thank the Legatum Institute and the Legatum Foundation for funding this work, as well as Julissa Milligan for assistance with statistical analysis in the manuscript. The authors also thank Harparkash Kaur, Albert van Wyk and Naiela Malik of the London School of Hygiene and Tropical Medicine for conducting HPLC analysis and Dr Kaur for editing the manuscript. 


\section{Disclosure}

The authors report no conflicts of interest in this work.

\section{References}

1. Roll Back Malaria Partnership. Updated ACT prices under the Affordable Medicines Facility - malaria, March 1, 2011: fact sheet. Geneva: The RBM Partnership; March 2011. Available from: http://www.theglobalfund. org/en/amfm/. Accessed May 7, 2012.

2. Bate R, Hess K. Anti-malarial drug quality in Lagos and Accra: a comparison of various quality assessments. Malar J. 2010;9:157.

3. Bate R, Hess K, Mooney L. Antimalarial medicine diversion: stock-outs and other public health problems. Res Rep Trop Med. 2010; 2010(1):19-24.

4. Lon CT, Tsuyuoka R, Phanouvong S, et al. Counterfeit and substandard antimalarial drugs in Cambodia. Trans R Soc Trop Med Hyg. 2006; 100(11):1019-1024.

5. Ioset JR, Kaur H. Simple field assays to check quality of current artemisinin-based antimalarial combination formulations. PLOS ONE. 2009;4(9):e7270.

6. World Health Organization. The International Pharmacopoeia - Fourth Edition (incl. First and Second Supplements). 2011. Available from: http://apps.who.int/phint/html/copyrighten.htm. Accessed June 22, 2012.

7. The Global Fund to Fight AIDS, TB and Malaria. Report of the AMFm Ad Hoc Committee. 2011 May 11-12. Available from: http://www. theglobalfund.org/en/board/meetings/twentythird/documents/. Accessed May 7, 2012.
8. Ghana Health Service. Latest News in Health Bullettin Upper East Region - Ghana: Affordable Medicines Facility for Malaria. 2011 June. Available from: http://www.ghanahealthservice.org/documents/ AMFm\%20Launch.pdf. Accessed May 7, 2012.

9. Health Action International. Retail prices of ACTs co-paid by the AMFm and other antimalarial medicines in Ghana, Kenya, Nigeria and Tanzania: Report of price-tracking surveys. 2011 June. Available from: http://www.theglobalfund.org/en/amfm/pricetracking/. Accessed May 7, 2012.

10. Newton P, Green M, Mildenhall D, et al. Poor quality vital antimalarials in Africa - an urgent neglected public health priority. Malar J. 2011;10:352.

11. Bate R, Coticelli P, Tren R, Attaran A. Antimalarial Drug Quality in the Most Severely Malarious Parts of Africa - A Six Country Study. PLoS ONE. 2008;3(5):e2132.

12. Bate R, Mooney L, Hess K, Milligan J, Attaran A. Anti-infective medicine quality: Analysis of basic product quality by approval status and country of manufacture. Research and Reports in Tropical Medicine. In press 2012.

13. The Global Fund to Fight AIDS, TB and Malaria. Affordable Medicines Facility - malaria (AMFm): Summary Report on Co-paid ACTs. Available from: http://portfolioreports.cloudapp.net/AMFm_Summary.aspx. Accessed May 7, 2012.

14. The Global Fund to Fight AIDS, TB and Malaria. Report of the Affordable Medicines Facility - Malaria (AMFm) Ad Hoc Committee (AHC). 2009 November 9-11. Available from: http://www.theglobalfund.org/ en/board/meetings/twentieth/documents/. Accessed May 7, 2012.
Research and Reports in Tropical Medicine

\section{Publish your work in this journal}

Research and Reports in Tropical Medicine is an international, peerreviewed, open access journal publishing original research, case reports, editorials, reviews and commentaries on all areas of tropical medicine, including: Diseases and medicine in tropical regions; Entomology; Epidemiology; Health economics issues; Infectious disease; Laboratory

\section{Dovepress}

science and new technology in tropical medicine; Parasitology; Public health medicine/health care policy in tropical regions; and Microbiology. The manuscript management system is completely online and includes a very quick and fair peer-review system. Visit http://www.dovepress. com/testimonials.php to read real quotes from published authors. 